\title{
Accidents in the Aluminium Smelting Industry
}

\author{
Bhuban C. DAS ${ }^{*}$ and Susama CHAUDHURY \\ Department of Occupational Health, \\ All India Institute of Hygiene \& Public Health, \\ 110, Chittaranjan Avenue, Calcutta 700 073, India
}

(Received March 23, 1995 and in revised form October 9, 1995)

\begin{abstract}
Analysis of the accident records of an aluminium smelting industry, covering about 2,100 employees, over a period of three years, showed a total of 465 accidents of male employees. Out of these, 5 were fatal, $40.86 \%$ were from contacts with extreme temperatures, causing burn injury to $42.58 \%$. Hot materials were the agents causing $44.52 \%$ of the burn injuries. Molten aluminium constituted $43.96 \%$ amongst hot materials. Injury to lower limbs constituted $38.71 \%$ and that to upper limbs $36.99 \%$. The accidents occurring to the employees, in the age group of 26-33 years, amounted to $61.72 \%$ of the total accidents.

The average number of man-days lost per year was 11,153. Average frequency rate of accidents was 30.75 accidents per million man'hours worked. Severity rate of accidents was 2,196 per million man'hours worked. Incident rate per thousand employees was 73.81 . Average number of days lost per accidents was 71.95 days and average duration of man'hours between accidents was 32,516. Mean age of the employees, who met with the accidents were 29.53 years. Share of accidents in the second half of each shift was always more than that in the first half, and this average was $66.66 \%$.
\end{abstract}

Key words: Aluminium Smelting - Accident - Burn - Agency causing injury - Parts of body injured - Man.days lost - Mean age - Shift

\section{INTRODUCTION}

The aluminium smelting industry has appropriate accident reporting procedure. The accident report contains information about name of the person, age, department, designation, parts of body injured, cause, date and duration of disablement. The types of work performed in different fields of occupation vary widely. The work entails heavy manual work in stressful working conditions. The reporting procedure has made it possible to relate injury rates to occupation and to search for the factors causing accidents.

\footnotetext{
* To whom correspondence should be addressed
} 
Aluminium is produced by employing Hall-Heroult Process where the alumina is subjected to electrolytic reduction ${ }^{2}$. Refined alumina obtained from bauxite ore is dissolved in a molten bath of cryolite, sodium aluminium fluoride, that serves as electrolyte. When electric current is passed through the carbon-lined reaction bath the aluminium metal is liberated and collected at the bottom, being slightly more dense than the electrolyte. The molten aluminium is tapped, alloyed and cast into ingots and parts of different shapes.

The main hazardous factors present in this process are splash of liquid aluminium from bath during tapping, overflow from ladle, explosion in contact with moisture, hot anode flying fragments while cutting, coming in contact with hot ingots and parts cast into shapes, presence of oily floors and unsafe house keeping.

The objective of this study was to determine the kind of occupation in the industry suffering the highest accident rate, and the type of accident most frequently encountered in the hazardous occupations.

The pattern of accidents thus established might permit detailed investigation of the causes of accidents and indicate effective measures to prevent recurrence.

\section{Methods}

This is an analysis of 465 cases of accidents which occurred from January 1989 to December 1991, the details of which were collected from the records and registers of the safety department and hospital records of an aluminium smelter in Eastern India.

The accident injury report is prepared by the supervisor or the person concerned, the shift in charge during which the event occurred. They certified that the injury of the employee occurred during the working hours and as a result of the employment. This report, along with the injured person, is forwarded to the medical officer who put his remarks about date and time, nature and extent of injury, influence of drinks or drugs, if any, period of rest advised and treatment given. Each accident is investigated jointly by the responsible person of the shift in charge and safety officer and the report is prepared within 24 hours.

Once the injured employee is fully cured, he reports his recovery to the medical officer. The medical officer examines him and declares whether he is fit or unfit to resume normal duty. The fitness certificate is forwarded to the personnel department, sectional head and safety department.

The records thus collected were coded so that these could be analysed subsequently for age, occupation, date of accident, time, shift, sick leave required, cause of injury, part of body affected, nature of injury, type of injury and agency. Detailed analysis of accidents were limited to only those resulting in absence of the employees from work of one day or more. The frequency rate, severity rate, incident rate, mean duration rate, duration rate and man-days lost was also calculated. These statistical terms were defined by the following equations $\mathrm{s}^{4,5)}$. 
$1^{*}$ Frequency rate $=\frac{\text { Total Number of Accidents } \times 1,000,000}{\text { Total Number of man } \cdot \text { hours worked }}$

(Number of hours per shift is taken as 8 for 300 working days in a year for each employee)

$2^{*}$ Severity rate $=$

Man-days lost due to accidents x $1,000,000$

Total number of man.hours worked

$3^{*}$ Incident rate $=\quad \frac{\text { Total number of accidents } \times 1,000}{\text { Number of persons employed }}$

$4^{*}$ Mean duration rate $=\frac{\text { Total number of days lost }}{\text { Total number of accidents }}$

(i.e., average number of days lost per accident)

$\begin{array}{ll}5^{*} \text { Duration rate }=\quad & \frac{\text { Number of man } \cdot \text { hours worked }}{\text { Total number of accidents }} \\ \text { (i.e., average number of man } \cdot \text { hours between accidents) }\end{array}$

RESULTS

During the period of 36 months out of 465 number of one day plus accidents, 38 patients needed one day sick leave, 366 patients needed two to ten days sick leave, 12 patients eleven to nineteen days and rest 49 patients needed twenty days or more sick leave.

Table 1 summarises the distribution of accidents by type and man days lost ${ }^{3,4}$. The most frequent type of accidents had occurred from contacts with extreme temperatures $(40.86 \%)$ of the molten aluminium, hot aluminium ingot, hot water, steam and hot anode fragments followed by those due to fall of objects or being struck by objects $(21.08 \%)$ and fall of person $(17.20 \%)$.

The man-days lost was highest $(40.85 \%)$ in contact with extreme temperatures followed by fall of person $(37.40 \%)$ and fall of objects or being struck by objects $(19.93 \%)$.

Table 2 shows the different agencies causing injury ${ }^{1,4)}$. Hot materials include molten aluminium metal, hot ingot, hot water, steam and hot anode fragments caused highest percentage of accidents $(44.52 \%)$ followed by those caused by tools and equipments like scraper, chisel, hammer, pipe wrench, allen keys, shovel and crow-bar $(14.62 \%)$. Working surface \& floor openings which included uncovered opening, oily floor and platform, broken road and floor were responsible for $9.89 \%$ of the accidents. The lifting machines, wheeled transport used in material han- 
Table 1. Distribution of number of accidents by type and man-days lost.

\begin{tabular}{lcccc}
\hline Types of accident & $\begin{array}{c}\text { Number of } \\
\text { accidents }\end{array}$ & $\%$ & man-days lost & $\%$ \\
\hline $\begin{array}{l}\text { Step-in on or striking against } \\
\text { object }\end{array}$ & 16 & 3.44 & 61 & 0.18 \\
$\begin{array}{l}\text { Caught in between objects } \\
\text { Fall of persons }\end{array}$ & 37 & 7.96 & 304 & 0.91 \\
$\begin{array}{l}\text { Fall of objects or struck by } \\
\text { objects }\end{array}$ & $80(2)$ & 17.20 & 12,515 & 37.40 \\
$\begin{array}{l}\text { Contact with extreme } \\
\text { temperature }\end{array}$ & $98(1)$ & 21.08 & 6,670 & 19.93 \\
$\begin{array}{l}\text { Exposure to or contact with } \\
\text { electric current }\end{array}$ & $190(2)$ & 40.86 & 13,668 & 40.85 \\
$\begin{array}{l}\text { Exposure to or contact with } \\
\text { harmful substances }\end{array}$ & 10 & 3.66 & 72 & 0.22 \\
Miscellaneous & 17 & 2.15 & 56 & 0.17 \\
Total & $465(5)$ & 100.00 & 33,460 & 100.00 \\
\hline
\end{tabular}

Figures in the parenthesis represent fatal accidents and included in the main figure.

Table 2. Distribution of accidents by agency.

\begin{tabular}{lcc}
\hline Agency & Number of accidents & $\%$ \\
\hline Power driven machines & 27 & 5.81 \\
Lifting machines and wheeled transport & 41 & 8.82 \\
Tools \& equipments & 68 & 14.62 \\
Materials \& substances & 41 & 8.82 \\
Hot materials & 207 & 44.52 \\
Working surface \& floor openings & 46 & 9.89 \\
Miscellaneous & 35 & 7.53 \\
& & \\
Total & 465 & 100.00 \\
\hline
\end{tabular}

dling, the crane, loader, fork lift, trucks, hand trolley etc. and materials \& substances such as aluminium ingot and coil, loose machine parts, empty drums contributed their share of accidents to the extent of $8.82 \%$.

Power driven machines having dangerous parts like rotating belts and pulleys, gears, grinding wheels, conveyor belts, tool holders, constitute lowest percentage $(5.81 \%)$ of accidents.

Table 3 represents the parts of body injured by accidents ${ }^{7)}$. The highest percentage $(38.71 \%)$ is the accidents to lower limbs. Further analysis showed that injuries at foot, ankle and leg were $52 \%, 17 \%$ and $19 \%$ of the lower limb inju- 
ries respectively. The second highest $(36.99 \%)$ percentage of the accidents that caused injuries to upper limbs were injuries to arms and fingers. These caused $47 \%$ and $30 \%$ of the upper limb accidents respectively.

The cause of injuries to upper and lower limbs were the improper use of the personal protective equipments thus failing to protect limbs from injury.

From the nature of injuries as shown in Table 4, $42.58 \%$ of the accidents are contributed by burns, caused mainly by molten aluminium metal drops, spilled aluminium from the ladle and tapping lid, hot anode mushroom fragment, hot water, steam and electricity ${ }^{4}$. The single largest item, in this group of accidents, was by burns from the molten aluminium $(43.96 \%)$ followed by hot anode mushroom fragments $(22 \%)$ and hot aluminium ingot (15\%).

Reasons for the burn injuries were, carelessness, improper fitting and/or nonuse of the personal protective equipments. The injuries due to burn caused to the lower limbs at foot, ankle, leg and to upper limbs, at finger and arm are mostly due to either by the molten metal entering the uncovered portion of the body either

Table 3. Distribution of accidents by part of body injured.

\begin{tabular}{lcc}
\hline Parts of body injured & Number of accidents & $\%$ \\
\hline Head, face and eye & 54 & 11.61 \\
Neck and trunk & 24 & 5.16 \\
Upper limb & 172 & 36.99 \\
Lower limb & 180 & 38.71 \\
Multiple locations & 35 & 7.53 \\
\hline
\end{tabular}

Table 4. Distribution of accidents by nature of injury.

\begin{tabular}{lrrrrr}
\hline Nature of injury & Years: 1989 & 1990 & 1991 & Total & $\%$ \\
\hline Fracture & 7 & 3 & 7 & 17 & 3.66 \\
Sprains & 17 & 13 & 13 & 43 & 9.25 \\
Amputations & 1 & - & - & 1 & 0.22 \\
Laceration & 25 & 23 & 27 & 75 & 16.13 \\
Superficial injuries & 20 & 6 & 7 & 33 & 7.10 \\
Contusions \& crushings & 13 & 22 & 25 & 60 & 12.90 \\
Burns & 61 & 67 & 70 & 198 & 42.58 \\
Electric shock & 3 & 1 & 1 & 5 & 1.08 \\
Multiple injuries & 6 & 9 & 1 & 16 & 3.44 \\
& 1 & 12 & 4 & 17 & 3.66 \\
Others & & & & & \\
Total & 154 & 156 & 155 & 465 & 100.00 \\
\hline
\end{tabular}


because of shorter length of the leg-guard, safety shoes, hand gloves, sleeves and wrist-lets or non use of these.

To bring down the incidence of these accidents, strict compliance to the safety rules, regular inspection and maintenance of the metal handling pots and machinery should be enforced. Proper use of personal protective equipments like, legguards, safety shoes, ankle guards, safety pants and shirts, hand gloves, helmets, goggles is to be ensured.

To educate the workers and make them safety conscious, intense campaigning with audio-visual aids and safety education programmes should be arranged for the group of employees mostly comprising of labourers, trainees, technicians, operators, drivers who are exposed more to the risk of accidents than others due to their nature of work in pot line, cast house and carbon plant shop.

Man-days lost, Frequency rate, Severity rate, Incident rate, Mean duration rate and Duration rate of accidents, has been shown for each year in Table 5. Yearly average Frequency rate was 30.75 per million man hours worked, Severity rate was 2,196 per million man'hours worked. Incident rate per thousand employees was 73.81, Mean duration rate was 71.95, Duration rate was 32,516 and Man-days lost 11,153 .

Figure 1 shows the distribution by age group ${ }^{7)}$. Majority of the accidents, $61.72 \%$, occurred in the age group 26-33 years followed by 18-25 year of age group, $21.89 \%$. The mean and standard deviation of the age of accident is 29.53 \pm 4.52 .

Figure 2 displays the distribution of accidents in different shifts ${ }^{6)}$. The highest share of accidents was in "B" shift (32.26\%) followed by "A" shift $(28.60 \%)$ and in all the shifts accidents were more in the second half in comparison to the first half.

\section{CONCLUSION}

The important observation of this analysis has been the high incidences of burn

Table 5. Man·days lost, Frequency rate, Severity rate, Incident rate, Mean duration rate and Duration rate of accidents during 1989-1991.

\begin{tabular}{lcccccccc}
\hline Year & $\begin{array}{c}\text { Number } \\
\text { of } \\
\text { accidents }\end{array}$ & $\begin{array}{c}\text { Number } \\
\text { of } \\
\text { employees }\end{array}$ & $\begin{array}{c}\text { Man } \\
\text { days } \\
\text { lost }\end{array}$ & $\begin{array}{c}\text { Frequency } \\
\text { rate } 1^{*}\end{array}$ & $\begin{array}{c}\text { Severity } \\
\text { rate } 2^{*}\end{array}$ & $\begin{array}{c}\text { Incident } \\
\text { rate } 3^{*}\end{array}$ & $\begin{array}{c}\text { Mean } \\
\text { duration } \\
\text { rate } 4^{*}\end{array}$ & $\begin{array}{c}\text { Duration } \\
\text { rate } 5^{*}\end{array}$ \\
\hline 1989 & 154 & 1,993 & 7,106 & 32.20 & 1,486 & 77.27 & 46.14 & 31,060 \\
1990 & 156 & 2,112 & 13,196 & 32.55 & 2,603 & 73.86 & 84.59 & 32,492 \\
1991 & 155 & 2,195 & 13,158 & 29.42 & 2,498 & 70.62 & 84.89 & 33,987 \\
& & & & & & & & \\
Average & 155 & 2,100 & 11,153 & 30.75 & 2,196 & 73.81 & 71.95 & 32,516 \\
\hline
\end{tabular}




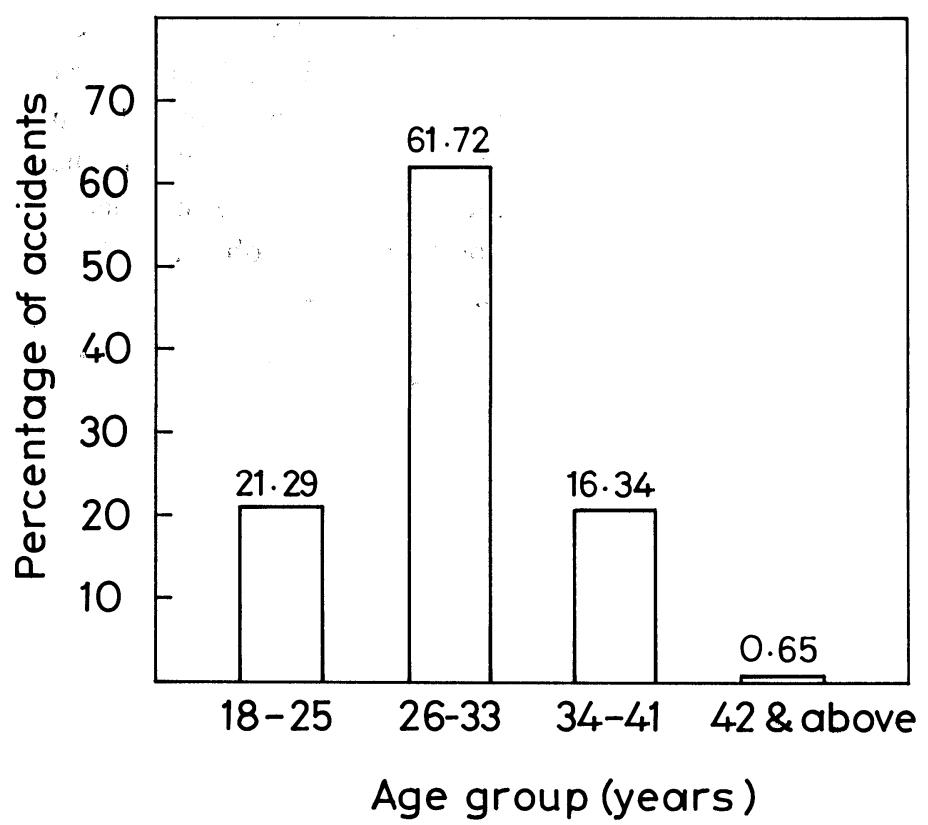

Fig. 1. Distribution of accidents by age group. Total number of accidents was 465 . The mean and standard deviation of the age of accident occurrence is $29.5 \pm 4.5$.

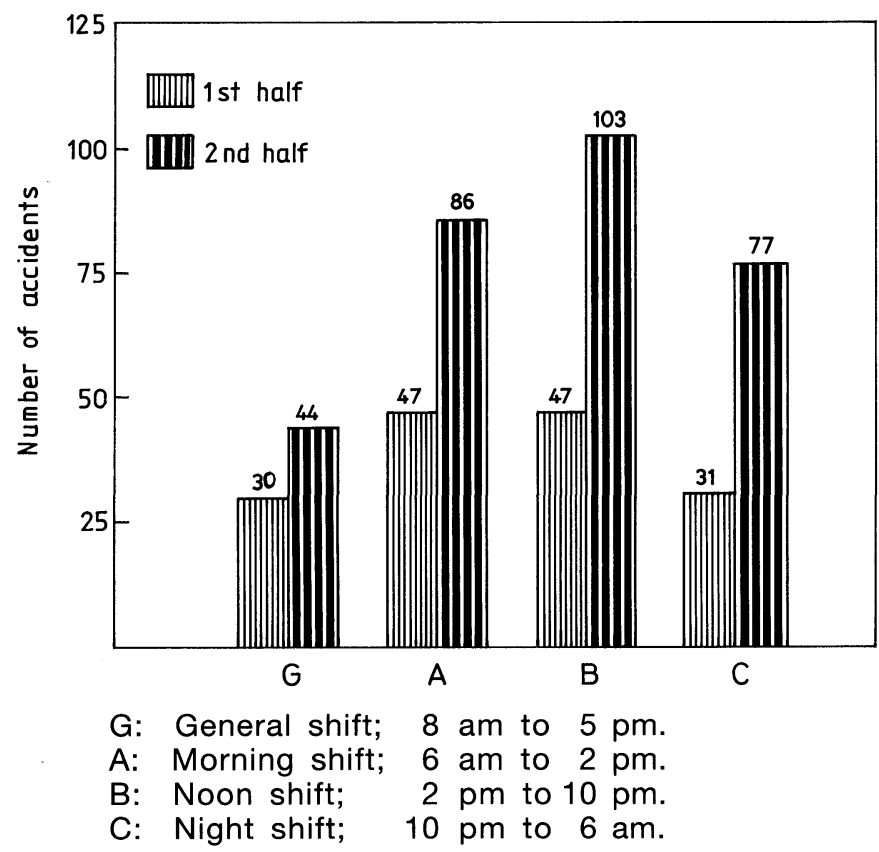

Fig. 2. Distribution of accidents in the work shifts. 
injuries and laceration at $42.58 \%$ and $16.13 \%$ respectively. It is seen that most of the injuries are located in the lower limbs (38.71\%) and upper limbs (36.99\%) of the body. These generally occurred as the employees were either not provided with suitable personal protective equipments or failed to use them when provided.

It is revealed that the most important causes of injury are, contact with extreme temperatures $(40.86 \%)$, falling of objects or stricken by objects $(21.08 \%)$ and fall of persons $(17.20 \%)$ which together account for $79.14 \%$ of the accidents occurred and $98.18 \%$ of the man.hour lost.

The findings show that the largest part of the accidents occur due to hot materials (44.52\%), followed by tools and equipments $(14.62 \%)$ which together amounted to $59.14 \%$ in combination against the total. The common causes of these accidents are adoption of unsafe techniques for handling hot objects and hand tools.

It is seen that the accidents in the second half in each shift is more than the first half. It is mostly due to work fatigue and monotony of the work leading to carelessness.

Majority of the accidents, $(61.72 \%)$ out of 465 , occurred to persons in the age group 26-33 years. This is because the majority of the persons are in this age group and a major portion of the physical work is performed by them.

\section{ACKNOWLEDGMENTS}

The authors express their sincere thanks to the management of the factory, especially Safety Engineering and Personnel Departments for making available the data used in the study. We are very grateful to the Chief Medical Officer, Doctors and Office Staffs of the Hospital for their help for providing us with necessary information. We would thank Dr. SR Dutta, Head of the Department of Occupational Health and the Director of All India Institute of Hygiene \& Public Health, Calcutta, for the permission granted, encouragement given and interest shown in the work.

\section{REFERENCES}

1) Biswas SK. Study of accidents in iron industry. Indian J Ind Medicine 1960; 6: 4: 119-27.

2) Cralley LV, Cralley LJ. Industrial Hygiene aspects of plant operations. Vol. 1. New York: Macmillan Publishing Co. 1984; 47-59.

3) Davis PR, Sheppard NJ. Pattern of accident distribution in the telecommunication industry. $\mathrm{Br}$ J Ind Med 1980; 37: 175-9.

4) I S I, Method of computation of frequencies of severity rates for industrial injuries and classification of industrial accidents. IS: 3786, 1966; 4-24.

5) Ridley JR. Safety at work. 3rd ed. England: Butterworth-Heinemann, 1990; 223-8.

6) Sabins CV, Rao MN. Accidents in Indian Industry Trend and Prevention. Swasth Hind 1961; 5: $81-8$.

7) Saha M. Accident in copper industry. Indian J Ind Med 1991; 37: 156-63. 